\title{
Spleen Dose-Volume Parameters as a Predictor of Treatment-related Lymphopenia During Definitive Chemoradiotherapy for Esophageal Cancer
}

\author{
TETSUO SAITO ${ }^{1}$, RYO TOYA ${ }^{1}$, NAOYA YOSHIDA ${ }^{2}$, TAKASHI SHONO ${ }^{3}$, TOMOHIKO MATSUYAMA ${ }^{1}$, \\ SATOSHI NINOMURA ${ }^{1}$, TAKAHIRO WATAKABE ${ }^{1}$, YUTAKA SASAKI ${ }^{3}$, HIDEO BABA $^{2}$ and NATSUO OYA ${ }^{1}$ \\ ${ }^{1}$ Department of Radiation Oncology, Kumamoto University Hospital, Kumamoto, Japan; \\ Departments of ${ }^{2}$ Gastroenterological Surgery, and ${ }^{3}$ Gastroenterology and Hepatology, \\ Graduate School of Medical Sciences, Kumamoto University, Kumamoto, Japan
}

\begin{abstract}
Aim: Our study sought to identify dosimetric predictors of treatment-related lymphopenia during chemoradiotherapy for esophageal cancer. Materials and Methods: Patients with esophageal cancer who had received definitive chemoradiotherapy at our Institution were retrospectively assessed. The absolute volume of the spleen, body, and bone marrow that had received 5, 10, 20, and 30 Gy and the mean splenic dose were recorded. Results: Multivariate linear regression analysis revealed that docetaxel use and spleen dose-volume parameters (V5, V10, V20, V30, and mean splenic dose) were significant independent factors negatively influencing the absolute lymphocyte count at nadir. An increase of 1 Gy in mean splenic dose predicted a $2.9 \%$ decrease in nadir absolute lymphocyte count. Univariable logistic regression analysis showed that the mean splenic dose was a significant predictor of grade 4 lymphopenia. None of the body or bone marrow dose-volume parameters significantly predicted lymphopenia. Conclusion: Higher spleen dose-volume parameters were associated with severe lymphopenia during chemoradiotherapy.
\end{abstract}

The important role of lymphocytes in the immune response to cancer is evidenced by reports that show better survival of patients with lung, colorectal, and breast cancer who have

This article is freely accessible online.

Correspondence to: Tetsuo Saito, MD, Department of Radiation Oncology, Kumamoto University Hospital, 1-1-1, Honjo, Chuo-ku, Kumamoto-shi, Kumamoto, 860-8556, Japan. Tel: +81 963735261, Fax: +81963735342, e-mail: tsaito@kumamoto-u.ac.jp

Key Words: Treatment-related lymphopenia, chemoradiotherapy, spleen, bone marrow, dose-volume parameters. lymphocyte infiltration in the tumor tissue (1-3). Recent studies demonstrated that treatment-related lymphopenia was associated with poor outcome in patients undergoing definitive chemoradiotherapy (CRT) for esophageal, pancreatic, lung, cervical, and nasopharyngeal cancer (4-8). Lymphocytes are highly radiosensitive, and exposure to low doses of radiation can lead to a decrease in the number of peripheral blood lymphocytes (9). Radiation-related lymphopenia can thus affect the immune system and the treatment outcome.

Previous studies have suggested that radiation-related lymphopenia is associated with the irradiation of lymphoid tissue including the spleen (10) and bone marrow (11), or the irradiation of peripheral blood lymphocytes $(12,13)$. However, in CRT for esophageal cancer, mechanisms of treatment-related lymphopenia have not been clarified. Therefore, focusing on dose-volume parameters, we sought to identify predictors of lymphopenia during CRT for esophageal cancer.

\section{Materials and Methods}

Patients. This retrospective study was approved by the Institutional Review Board of our hospital (approval number, 1533). Patient informed consent was waived due to the retrospective nature of the study. The study was carried out according to the Declaration of Helsinki. Our inclusion criteria were as follows: Patients who completed definitive CRT for esophageal cancer between January 2011 and August 2015 and whose chemotherapy regimen included cisplatin. The exclusion criteria were: Previous radiotherapy (RT); chemotherapy performed before CRT; and CRT performed as preoperative treatment.

Laboratory data. The study endpoints were as follows: (i) the absolute lymphocyte count (ALC) at nadir, defined as the lowest value recorded during CRT; and (ii) lymphopenia of grade 4 (ALC $\left.<0.200 \times 10^{9} / \mathrm{I}\right)$ as determined by the Common Terminology Criteria for Adverse Events v 4.0, (14) with the highest grade during the CRT recorded for analysis. 
Dose-volume parameters. Three organs at risk were assessed: Spleen, body, and bone marrow. For the present study, organs at risk were delineated on planning computed tomographic images using commercially available software (Velocity AI; Velocity Medical System, Atlanta, GA, USA). One radiation oncologist delineated the spleen manually. For delineating the body and bone marrow, a previously described method was followed (13). In order to evaluate the effect of radiation on peripheral blood lymphocytes, the radiation oncologist delineated the volume enclosed by the body surface, creating a body contour. The body surface contour was obtained first using threshold-based segmentation and then by manual correction. For bone marrow, all bones were delineated by threshold-based segmentation and manual correction; intervertebral disks and costal, thyroid, cricoid, and tracheal cartilage were excluded. The absolute volume of the three organs at risk receiving 5, 10, 20, and 30 Gy (V5, V10, V20, and V30) was recorded. The mean splenic dose was also calculated.

Statistical analysis. For univariable and multivariable linear regression analyses and univariable logistic regression analysis, patient age, body mass index, baseline ALC, and dose-volume parameters were applied as continuous variables. The categorical variables included the American Joint Committee on Cancer clinical stage (15) and the concurrent chemotherapy regimen. The ShapiroWilk statistic was used to check the normality assumption of residuals and to judge if any variable transformation was necessary. The variance inflation factor was used to detect multicolinearity between independent variables. All variables with a $p$-value less than 0.1 at univariable linear regression analysis were entered into multivariable analysis. Spearman correlation coefficients were used to evaluate associations between the spleen dose-volume parameters and the ALC at nadir. The overall survival, calculated from the start of RT, was estimated using the Kaplan-Meier method; differences in survival were determined with the log-rank test. All tests were two tailed, and differences with $p<0.05$ indicated statistical significance. All statistical analyses were performed using SPSS software, version 24 (IBM SPSS, Armonk, NY, USA).

\section{Results}

Patients. The study population included 61 patients treated with definitive CRT for esophageal cancer (Table I). All patients had squamous cell carcinoma.

Laboratory data. Blood samples were collected at least weekly during CRT. The median pre-CRT ALC was $1.638 \times 10^{9} / 1 \quad$ range $\left.=0.585-3.226 \times 10^{9} / 1\right)$, and the median nadir ALC during CRT was $0.134 \times 10^{9} / 1$ (range $=0.029$ $\left.0.372 \times 10^{9} / 1\right)$. Of the 61 patients, $48(79 \%)$ developed grade 4 lymphopenia; the other 13 patients $(21 \%)$ developed grade 3 lymphopenia.

Dose-volume parameters. The median (range) V5, V10, V20, and V30 of the spleen were 12 (0-139), 6 (0-120), 2 (0102), and 0 (0-63) $\mathrm{ml}$, respectively. These values were 67.65 (28.84-122.09), 56.54 (24.18-107.51), 43.57 (18.63-88.38), and $35.25(12.62-69.27) \times 10^{2} \mathrm{ml}$ for the body, and 7.71 (3.00-11.74), 6.53 (2.56-10.89), 5.62 (2.10-9.79), and 4.93
Table I. Patient and treatment characteristics $(n=61)$.

\begin{tabular}{|c|c|}
\hline Characteristic & Value \\
\hline \multicolumn{2}{|l|}{ Age, years } \\
\hline Median (range) & $68(45-88)$ \\
\hline \multicolumn{2}{|l|}{ Gender, n (\%) } \\
\hline Female & $7(11)$ \\
\hline Male & $54(89)$ \\
\hline \multicolumn{2}{|l|}{ Body mass index, $\mathrm{kg} / \mathrm{m}^{2}$} \\
\hline Median (range) & $21.6(15.1-47.8)$ \\
\hline \multicolumn{2}{|l|}{ Tumor location, $\mathrm{n}(\%)$} \\
\hline Cervical & $20(33)$ \\
\hline Upper thoracic & $11(18)$ \\
\hline Middle thoracic & $18(30)$ \\
\hline Lower thoracic & $12(20)$ \\
\hline \multicolumn{2}{|l|}{ AJCC clinical stage, n (\%) } \\
\hline I & $22(36)$ \\
\hline II & $10(16)$ \\
\hline III & $29(48)$ \\
\hline \multicolumn{2}{|l|}{ Baseline ALC $\left(\times 10^{9} / 1\right)$} \\
\hline Median (range) & $1.638(0.585-3.226)$ \\
\hline \multicolumn{2}{|l|}{ Elective nodal irradiation, $\mathrm{n}(\%)$} \\
\hline No & $8(13)$ \\
\hline Yes & $53(87)$ \\
\hline \multicolumn{2}{|l|}{ Radiotherapy technique, n (\%) } \\
\hline 3-D conformal radiotherapy & $56(92)$ \\
\hline $\begin{array}{l}\text { 3-D conformal radiotherapy and } \\
\text { intensity-modulated radiotherapy }\end{array}$ & $5(8)$ \\
\hline \multicolumn{2}{|l|}{ Total radiation dose, $\mathrm{n}(\%)$} \\
\hline $60 \mathrm{~Gy}$ & $39(64)$ \\
\hline $59.6 \mathrm{~Gy}$ & $22(36)$ \\
\hline \multicolumn{2}{|l|}{ Concurrent chemotherapy, n (\%) } \\
\hline Cisplatin + 5-fluorouracil & $20(33)$ \\
\hline Docetaxel + cisplatin +5 -fluorouracil & $41(67)$ \\
\hline
\end{tabular}

AJCC, American Joint Committee on Cancer (7th edition) (15); ALC, absolute lymphocyte count.

$(1.62-8.59) \times 10^{2} \mathrm{ml}$ for the bone marrow. The median (range) mean splenic dose was $2.87(0-31.77) \mathrm{Gy}$.

Predictors of treatment-related lymphopenia. As the ShapiroWilk test showed that the normality assumption of residuals was not met, ALC at nadir was log (base 10) transformed to meet the assumption; $\log _{10}$ ALC nadir was the dependent variable in our linear regression analyses. In univariable linear regression analysis, baseline ALC, docetaxel use, spleen V5, spleen V10, spleen V20, spleen V30, and mean splenic dose gave $p$-values of less than 0.10 (Table II), and were included in multivariable analysis. Since there were strong associations between spleen V5, spleen V10, spleen V20, spleen V30, and mean splenic dose, these variables were analyzed in separate models (Table III). Variance inflation factors ranged from 1.00 to 1.05 , and this indicated that there was no multicollinearity problem for the independent variables. Multivariable linear regression analysis showed that docetaxel use, spleen V5, 
Table II. Univariable linear regression analysis to identify variables associated with absolute lymphocyte count (ALC) nadir (log10 values).

\begin{tabular}{|c|c|c|c|}
\hline Variable & B & $95 \% \mathrm{CI}$ & $p$-Value \\
\hline Age (per 1 year increase) & 0.001 & $-0.007-0.008$ & 0.88 \\
\hline Body mass index (per $1 \mathrm{~kg} / \mathrm{m}^{2}$ increase) & 0.010 & $-0.003-0.023$ & 0.13 \\
\hline 7th AJCC clinical stage (III vs. I, II) & 0.019 & $-0.116-0.155$ & 0.78 \\
\hline Baseline ALC (per increase of $1 \times 10^{9} / 1$ ) & 0.096 & $-0.017-0.209$ & 0.093 \\
\hline Concurrent chemotherapy (DCF vs. CF) & -0.154 & $-0.293-0.015$ & 0.030 \\
\hline Spleen V5 (per increase of $1 \mathrm{ml}$ ) & -0.002 & $-0.004-0.000$ & 0.012 \\
\hline Spleen V10 (per increase of $1 \mathrm{ml}$ ) & -0.003 & $-0.005-0.001$ & 0.005 \\
\hline Spleen V20 (per increase of $1 \mathrm{ml}$ ) & -0.003 & $-0.006-0.000$ & 0.031 \\
\hline Spleen V30 (per increase of $1 \mathrm{ml}$ ) & -0.006 & $-0.011-0.001$ & 0.032 \\
\hline Mean splenic dose (per increase of $1 \mathrm{~Gy}$ ) & -0.011 & $-0.020-0.003$ & 0.008 \\
\hline Body V5 (per increase of $1 \times 10^{2} \mathrm{ml}$ ) & -0.001 & $-0.004-0.003$ & 0.60 \\
\hline Body V10 (per increase of $1 \times 10^{2} \mathrm{ml}$ ) & -0.002 & $-0.005-0.002$ & 0.45 \\
\hline Body V20 (per increase of $1 \times 10^{2} \mathrm{ml}$ ) & -0.001 & $-0.006-0.003$ & 0.56 \\
\hline Body V30 (per increase of $1 \times 10^{2} \mathrm{ml}$ ) & 0.001 & $-0.005-0.006$ & 0.83 \\
\hline Bone marrow V5 (per increase of $1 \times 10^{2} \mathrm{ml}$ ) & -0.015 & $-0.053-0.022$ & 0.42 \\
\hline Bone marrow V10 (per increase of $1 \times 10^{2} \mathrm{ml}$ ) & -0.025 & $-0.066-0.015$ & 0.21 \\
\hline Bone marrow V20 (per increase of $1 \times 10^{2} \mathrm{ml}$ ) & -0.028 & $-0.071-0.015$ & 0.19 \\
\hline Bone marrow V30 (per increase of $1 \times 10^{2} \mathrm{ml}$ ) & -0.009 & $-0.053-0.036$ & 0.70 \\
\hline
\end{tabular}

AJCC, American Joint Committee on Cancer; DCF, docetaxel + cisplatin + 5-fluorouracil; CF, cisplatin + 5-fluorouracil; $\beta$, regression coefficient; $\mathrm{CI}$, confidence interval; V5, volume receiving $5 \mathrm{~Gy}$; V10, volume receiving $10 \mathrm{~Gy}$; V20, volume receiving $20 \mathrm{~Gy}$; V30, volume receiving $30 \mathrm{~Gy}$.

Table III. Multivariable linear regression analysis to identify variables associated with log10 (ALC nadir).

\begin{tabular}{|c|c|c|c|c|}
\hline Model & Variable & $\beta$ & $95 \% \mathrm{CI}$ & $p$-Value \\
\hline \multirow[t]{3}{*}{1} & Baseline ALC (per increase of $1 \times 10^{9} / 1$ ) & 0.102 & $-0.002-0.206$ & 0.054 \\
\hline & Concurrent chemotherapy (DCF vs. CF) & -0.164 & $-0.293--0.034$ & 0.014 \\
\hline & Spleen V5 (per increase of $1 \mathrm{ml}$ ) & -0.003 & $-0.004--0.001$ & 0.001 \\
\hline \multirow[t]{3}{*}{2} & Baseline ALC (per increase of $1 \times 10^{9} / 1$ ) & 0.092 & $-0.012-0.196$ & 0.081 \\
\hline & Concurrent chemotherapy (DCF vs. CF) & -0.146 & $-0.275--0.017$ & 0.028 \\
\hline & Spleen V10 (per increase of $1 \mathrm{ml}$ ) & -0.003 & $-0.005--0.001$ & 0.001 \\
\hline \multirow[t]{3}{*}{3} & Baseline ALC (per increase of $1 \times 10^{9} / 1$ ) & 0.091 & $-0.017-0.199$ & 0.098 \\
\hline & Concurrent chemotherapy (DCF vs. CF) & -0.133 & $-0.267-0.001$ & 0.052 \\
\hline & Spleen V20 (per increase of $1 \mathrm{ml}$ ) & -0.003 & $-0.006--0.001$ & 0.017 \\
\hline \multirow[t]{3}{*}{4} & Baseline ALC (per increase of $1 \times 10^{9} / 1$ ) & 0.080 & $-0.028-0.188$ & 0.15 \\
\hline & Concurrent chemotherapy (DCF vs. CF) & -0.136 & $-0.271--0.001$ & 0.049 \\
\hline & Spleen V30 (per increase of $1 \mathrm{ml}$ ) & -0.006 & $-0.011--0.001$ & 0.025 \\
\hline \multirow[t]{3}{*}{5} & Baseline ALC (per increase of $1 \times 10^{9} / 1$ ) & 0.099 & $-0.005-0.203$ & 0.062 \\
\hline & Concurrent chemotherapy (DCF vs. CF) & -0.153 & $-0.282--0.024$ & 0.021 \\
\hline & Mean splenic dose (per increase of $1 \mathrm{~Gy}$ ) & -0.013 & $-0.021--0.005$ & 0.001 \\
\hline
\end{tabular}

ALC, Absolute lymphocyte count; DCF, Docetaxel + Cisplatin + 5-fluorouracil; CF, Cisplatin + 5-fluorouracil; $\beta$, regression coefficient; CI, confidence interval; V5, volume receiving 5 Gy; V10, volume receiving $10 \mathrm{~Gy}$; V20, volume receiving $20 \mathrm{~Gy}$; V30, volume receiving $30 \mathrm{~Gy}$.

spleen V10, spleen V20, spleen V30, and mean splenic dose were significant factors influencing $\mathrm{ALC}$ at nadir. In multivariable analysis, the regression coefficient for mean splenic dose was -0.013 ; an increase of $1 \mathrm{~Gy}$ in mean splenic dose predicted a $2.9 \%$ decrease in ALC at nadir. Univariable logistic regression analysis identified mean splenic dose as a significant predictor of grade 4 lymphopenia (Table IV).
Correlations between the spleen dose-volume parameters and ALC at nadir. There were significant correlations between the spleen dose-volume parameters and ALC at nadir (Figure 1).

Relationship between treatment-related lymphopenia and overall survival. The median follow-up period from the start 
in vivo $32: 1519-1525(2018)$

Table IV. Univariable logistic regression analysis to identify variables associated with grade 4 lymphopenia.

\begin{tabular}{|c|c|c|c|}
\hline Variable & OR & $95 \% \mathrm{CI}$ & $p$-Value \\
\hline Age (per 1 year increase) & 1.00 & $0.94-1.07$ & 0.94 \\
\hline Body mass index (per $1 \mathrm{~kg} / \mathrm{m}^{2}$ increase) & 0.95 & $0.85-1.06$ & 0.38 \\
\hline 7th AJCC clinical (stage III vs. I, II) & 0.49 & $0.14-1.70$ & 0.26 \\
\hline Baseline ALC (per increase of $1 \times 10^{9} / 1$ ) & 0.52 & $0.18-1.45$ & 0.21 \\
\hline Concurrent chemotherapy (DCF vs. CF) & 2.08 & $0.59-7.31$ & 0.25 \\
\hline Spleen V5 (per increase of $1 \mathrm{ml}$ ) & 1.02 & $1.00-1.04$ & 0.088 \\
\hline Spleen V10 (per increase of $1 \mathrm{ml}$ ) & 1.03 & $1.00-1.07$ & 0.094 \\
\hline Spleen V20 (per increase of $1 \mathrm{ml}$ ) & 1.06 & $0.98-1.15$ & 0.13 \\
\hline Spleen V30 (per increase of $1 \mathrm{ml}$ ) & 1.09 & $0.96-1.23$ & 0.21 \\
\hline Mean splenic dose (per increase of $1 \mathrm{~Gy}$ ) & 1.19 & $1.01-1.41$ & 0.037 \\
\hline Body V5 (per increase of $1 \times 10^{2} \mathrm{ml}$ ) & 1.01 & $0.98-1.04$ & 0.59 \\
\hline Body V10 (per increase of $1 \times 10^{2} \mathrm{ml}$ ) & 1.02 & $0.98-1.06$ & 0.43 \\
\hline Body V20 (per increase of $\left.1 \times 10^{2} \mathrm{ml}\right)$ & 1.02 & $0.97-1.07$ & 0.47 \\
\hline Body V30 (per increase of $\left.1 \times 10^{2} \mathrm{ml}\right)$ & 1.00 & $0.95-1.06$ & 0.92 \\
\hline Bone marrow V5 (per increase of $1 \times 10^{2} \mathrm{ml}$ ) & 1.07 & $0.76-1.50$ & 0.70 \\
\hline Bone marrow V10 (per increase of $1 \times 10^{2} \mathrm{ml}$ ) & 1.18 & $0.81-1.71$ & 0.39 \\
\hline Bone marrow V20 (per increase of $1 \times 10^{2} \mathrm{ml}$ ) & 1.24 & $0.82-1.87$ & 0.30 \\
\hline Bone marrow V30 (per increase of $1 \times 10^{2} \mathrm{ml}$ ) & 1.10 & $0.73-1.65$ & 0.65 \\
\hline
\end{tabular}

AJCC, American Joint Committee on Cancer; ALC, absolute lymphocyte count; OR, odds ratio; CI, confidence interval; V5, volume receiving 5 Gy; V10, volume receiving $10 \mathrm{~Gy}$; V20, volume receiving $20 \mathrm{~Gy}$; V30, volume receiving $30 \mathrm{~Gy}$.

of RT for the whole patient group was 31 months (range=2 to 83 months). There was no statistically significant difference in the overall survival of patients with grade 3 or lower lymphopenia (3-year overall survival=80\%) and those with grade 4 lymphopenia (3-year overall survival=73\%) $(\mathrm{p}=0.68)$.

\section{Discussion}

In this study, all patients who received CRT for esophageal cancer experienced severe treatment-related lymphopenia. We found that higher spleen dose-volume parameters were predictors of more severe lymphopenia during CRT for esophageal cancer. We also found that patients who received docetaxel in addition to cisplatin and 5-fluorouracil were more likely to experience severe lymphopenia.

The significant association we found between higher spleen dose-volume parameters and severe lymphopenia during CRT may be explained by the volume of lymphocytes that circulate through the spleen. The spleen is quantitatively the most important organ in the lymphoid system; more lymphocytes pass through this organ each day than through all lymph nodes (16). The transit time of lymphocytes migrating through the spleen is several-fold shorter than that through lymph nodes and therefore high numbers of lymphocytes home to and leave the spleen per day (16). Previous studies have reported that shortly following injection of labelled lymphocytes, up to $40 \%$ of the lymphocytes were found in the spleen (17-19). This quantitatively predominant role of the spleen in the lymphoid system may therefore explain our findings. Lymphocytes are highly radiosensitive, and previously reported in vitro data showed that the dose required to kill $50 \%$ of lymphocytes is approximately $2 \mathrm{~Gy}$, and that required to kill $10 \%$ of lymphocytes is approximately 0.5 Gy (20). This high sensitivity of lymphocytes to radiation means RT can cause substantial lymphocyte cell death even during the short transit time of lymphocytes through the spleen.

Our results suggesting the predictive value of spleen dosevolume parameters, are consistent with several studies. A study of 177 patients with locally advanced pancreatic cancer who received CRT demonstrated that higher splenic doses increased the risk of the development of severe post-CRT lymphopenia (10). A study of 59 patients with hepatocellular carcinoma demonstrated that higher spleen irradiation doses correlated significantly with lower minimum ALC during RT for hepatocellular carcinoma (21).

Accumulating evidence indicates that standard therapeutic doses of radiation have the potential to restore tumor immunogenicity and convert the tumor into an in situ 'personalized vaccine' (22). RT promotes cross-presentation of tumor-derived antigens by dendritic cells to T-cells, stimulates chemokine-mediated recruitment of effector Tcells to the tumor, and facilitates cellular recognition and killing by T-cells, especially when RT is combined with targeted immunotherapy (22). On the other hand, RT also has immune-suppressive effects, and causes lymphocyte cell death in lymphoid tissue or in the peripheral blood. To fully 

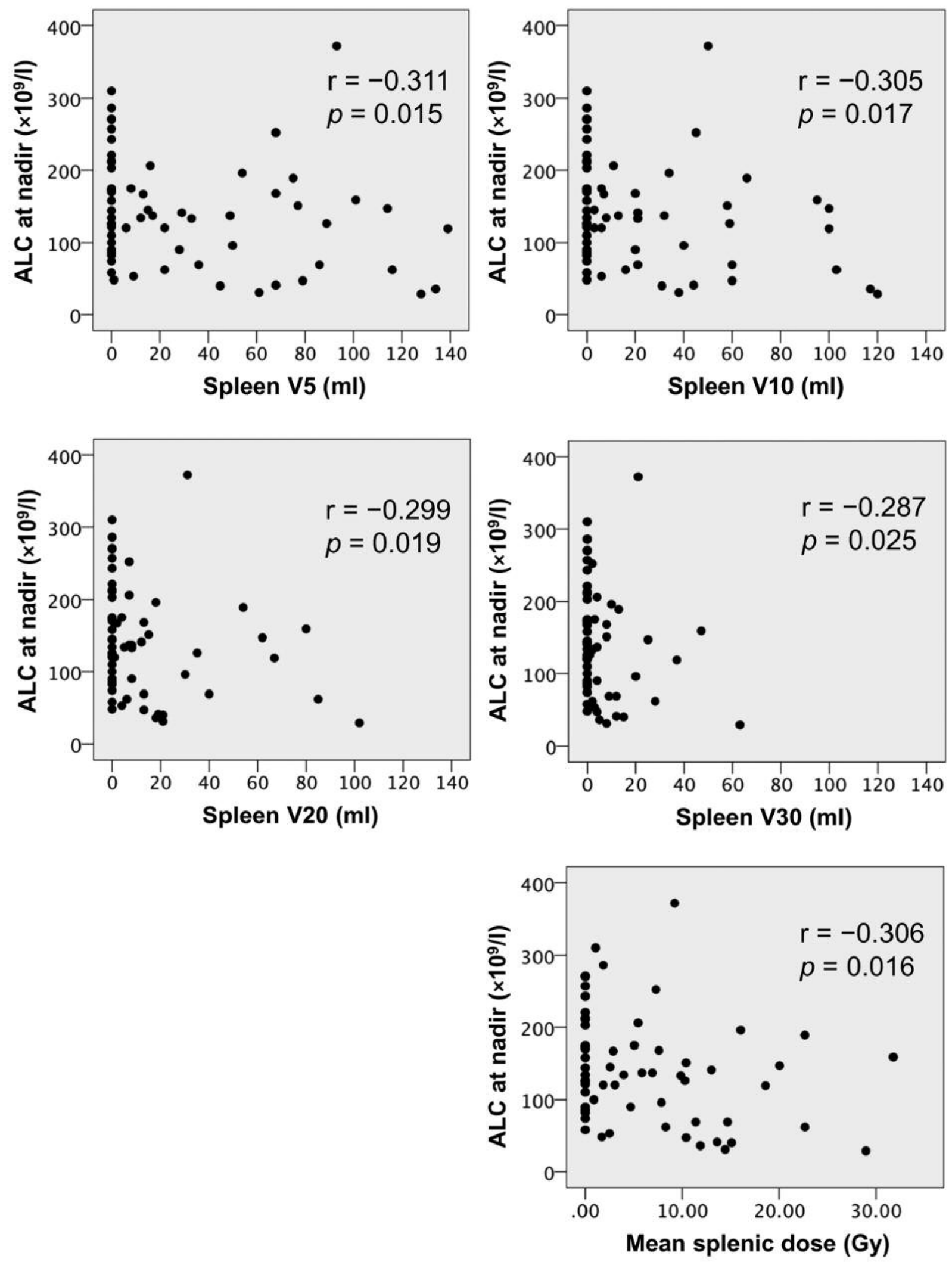

Figure 1. Spearman correlation coefficients $(r)$ were used to evaluate associations between spleen dose-volume parameters and absolute lymphocyte count $(A L C)$ at nadir. 
utilize the potential of RT to behave as an immune adjuvant, lymphocyte-sparing RT techniques should be used.

We found that patients who received docetaxel in addition to cisplatin and 5-fluorouracil were more likely to experience severe lymphopenia. Docetaxel has a direct, probably cytotoxic, effect on peripheral blood lymphocytes, and causes significant but reversible lymphopenia (23).

Severe treatment-related lymphopenia has been shown to be associated with worse survival and worse disease control in patients with various solid tumor types (24). In an analysis of patients with esophageal cancer who received neoadjuvant CRT, patients without grade 4 lymphopenia demonstrated evidence of prolonged disease-free and distant metastasis-free survival, and marginally also for better overall survival (4). It is unknown whether treatment-related lymphopenia has an influence on prognosis, or if it is only a prognostic factor.

Our study has some limitations. We did not find an association between treatment-related lymphopenia and survival. In our small study, the follow-up period was relatively short and a small number of deaths occurred. Our analysis may not have had enough statistical power to detect any clinically relevant difference. Another limitation of our retrospective study was that laboratory data were not acquired regularly during CRT. Consequently, we may not have used the true nadir blood cell counts in our analyses.

In summary, we retrospectively assessed dose-volume parameters of the spleen, body, and bone marrow for their ability to predict lymphopenia during CRT. Severe treatmentrelated lymphopenia occurred in our patients. Higher spleen dose-volume parameters were associated with more severe lymphopenia during CRT. Although the clinical relevance of lymphopenia needs to be studied further, our results may contribute to the development of lymphocyte-sparing RT techniques.

\section{Conflicts of Interest}

None declared.

\section{Acknowledgements}

This work was supported by the Japan Society for the Promotion of Science (Grants-in-Aid for Scientific Research; Grant Number 17K16458).

\section{References}

1 Hiraoka K, Miyamoto M, Cho Y, Suzuoki M, Oshikiri T, Nakakubo $\mathrm{Y}$, Itoh $\mathrm{T}$, Ohbuchi $\mathrm{T}$, Kondo $\mathrm{S}$ and Katoh $\mathrm{H}$ : Concurrent infiltration by CD8 + T-cells and CD4+ T-cells is a favourable prognostic factor in non-small-cell lung carcinoma. Br J Cancer 94: 275-280, 2006.

2 Ohtani H: Focus on TILs: prognostic significance of tumorinfiltrating lymphocytes in human colorectal cancer. Cancer Immun 7: 4, 2007.
3 Gu-Trantien C, Loi S, Garaud S, Equeter C, Libin M, de Wind A, Ravoet M, Le Buanec H, Sibille C, Manfouo-Foutsop G, Veys I, Haibe-Kains B, Singhal SK, Michiels S, Rothe F, Salgado R, Duvillier H, Ignatiadis M, Desmedt C, Bron D, Larsimont D, Piccart M, Sotiriou $C$ and Willard-Gallo K: $\mathrm{CD} 4(+)$ follicular helper $\mathrm{T}$-cell infiltration predicts breast cancer survival. J Clin Invest 123: 2873-2892, 2013.

4 Shiraishi Y, Fang P, Xu C, Song J, Krishnan S, Koay EJ, Mehran RJ, Hofstetter WL, Blum-Murphy M, Ajani JA, Komaki R, Minsky B, Mohan R, Hsu CC, Hobbs BP and Lin SH: Severe lymphopenia during neoadjuvant chemoradiation for esophageal cancer: A propensity-matched analysis of the relative risk of proton versus photon-based radiation therapy. Radiother Oncol 128: 154-160, 2017.

5 Wild AT, Ye X, Ellsworth SG, Smith JA, Narang AK, Garg T, Campian J, Laheru DA, Zheng L, Wolfgang CL, Tran PT, Grossman SA and Herman JM: The association between chemoradiation-related lymphopenia and clinical outcomes in patients with locally advanced pancreatic adenocarcinoma. Am J Clin Oncol 38: 259-265, 2015.

6 Tang C, Liao Z, Gomez D, Levy L, Zhuang Y, Gebremichael RA, Hong DS, Komaki R and Welsh JW: Lymphopenia association with gross tumor volume and lung V5 and its effects on non-small cell lung cancer patient outcomes. Int J Radiat Oncol Biol Phys 89: 1084-1091, 2014.

7 Wu ES, Oduyebo T, Cobb LP, Cholakian D, Kong X, Fader AN, Levinson KL, Tanner EJ, 3rd, Stone RL, Piotrowski A, Grossman S and Roche KL: Lymphopenia and its association with survival in patients with locally advanced cervical cancer. Gynecol Oncol 140: 76-82, 2016.

8 Cho O, Oh YT, Chun M, Noh OK, Hoe JS and Kim H: Minimum absolute lymphocyte count during radiotherapy as a new prognostic factor for nasopharyngeal cancer. Head Neck 38(Suppl 1): E1061-1067, 2016.

9 Trowell OA: The sensitivity of lymphocytes to ionising radiation. J Pathol Bacteriol 64: 687-704, 1952.

10 Chadha AS, Liu G, Chen HC, Das P, Minsky BD, Mahmood U, Delclos ME, Suh Y, Sawakuchi GO, Beddar S, Katz MH, Fleming JB, Javle MM, Varadhachary GR, Wolff RA, Crane $\mathrm{CH}$, Wang X, Thames H and Krishnan S: Does unintentional splenic radiation predict outcomes after pancreatic cancer radiation therapy? Int J Radiat Oncol Biol Phys 97: 323-332, 2017.

11 Sini C, Fiorino C, Perna L, Noris Chiorda B, Deantoni CL, Bianchi M, Sacco V, Briganti A, Montorsi F, Calandrino R, Di Muzio N and Cozzarini C: Dose-volume effects for pelvic bone marrow in predicting hematological toxicity in prostate cancer radiotherapy with pelvic node irradiation. Radiother Oncol 118: 79-84, 2016.

12 Yovino S, Kleinberg L, Grossman SA, Narayanan M and Ford E: The etiology of treatment-related lymphopenia in patients with malignant gliomas: Modeling radiation dose to circulating lymphocytes explains clinical observations and suggests methods of modifying the impact of radiation on immune cells. Cancer Invest 31: 140-144, 2013.

13 Saito T, Toya R, Matsuyama T, Semba A and Oya N: Dosimetric predictors of treatment-related lymphopenia induced by palliative radiotherapy: Predictive ability of dose-volume parameters based on body surface contour. Radiol Oncol 51: 228-234, 2017. 
14 National Cancer Institute: National Cancer Institute Common Terminology Criteria for Adverse Events version 4.0. http:// ctep.cancer.gov/protocolDevelopment/electronic_applications/ctc .htm\#ctc_40.

15 Edge SB and Compton CC: The American Joint Committee on Cancer: The 7th edition of the AJCC Cancer Staging Manual and the future of TNM. Ann Surg Oncol 17: 1471-1474, 2010.

16 Pabst R and Binns RM: Heterogeneity of lymphocyte homing physiology: Several mechanisms operate in the control of migration to lymphoid and non-lymphoid organs in vivo. Immunol Rev 108: 83-109, 1989.

17 Rannie GH and Donald KJ: Estimation of the migration of thoracic duct lymphocytes to non-lymphoid tissues. A comparison of the distribution of radioactivity at intervals following i.v. transfusion of cells labelled with $3 \mathrm{H}, 14 \mathrm{C}, 75 \mathrm{Se}$, 99mTc, $125 \mathrm{I}$ and $51 \mathrm{Cr}$ in the rat. Cell Tissue Kinet 10: 523-541, 1977.

18 Smith ME and Ford WL: The migration of lymphocytes across specialized vascular endothelium. VI. The migratory behaviour of thoracic duct lymphocytes retransferred from the lymph nodes, spleen, blood, or lymph of a primary recipient. Cell Immunol 78: 161-173, 1983.

19 Smith ME and Ford WL: The recirculating lymphocyte pool of the rat: a systematic description of the migratory behaviour of recirculating lymphocytes. Immunology 49: 83-94, 1983.

20 Nakamura N, Kusunoki Y and Akiyama M: Radiosensitivity of CD4 or CD8 positive human T-lymphocytes by an in vitro colony-formation assay. Radiat Res 123: 224-227, 1990.
21 Liu J, Zhao Q, Deng W, Lu J, Xu X, Wang R, Li X and Yue J: Radiation-related lymphopenia is associated with spleen irradiation dose during radiotherapy in patients with hepatocellular carcinoma. Radiat Oncol 12: 90, 2017.

22 Demaria S, Pilones KA, Vanpouille-Box C, Golden EB and Formenti SC: The optimal partnership of radiation and immunotherapy: From preclinical studies to clinical translation. Radiat Res 182: 170-181, 2014.

23 Kotsakis A, Sarra E, Peraki M, Koukourakis M, Apostolaki S, Souglakos J, Mavromanomakis E, Vlachonikolis $\mathrm{J}$ and Georgoulias V: Docetaxel-induced lymphopenia in patients with solid tumors: A prospective phenotypic analysis. Cancer 89: 1380-1386, 2000.

24 Venkatesulu BP, Mallick S, Lin SH and Krishnan S: A systematic review of the influence of radiation-induced lymphopenia on survival outcomes in solid tumors. Crit Rev Oncol Hematol 123: 42-51, 2018.
Received July 19, 2018

Revised August 6, 2018

Accepted August 7, 2018 